Max-Planck-Institut für demografische Forschung

Max Planck Institute for Demographic Research

Konrad-Zuse-Strasse 1 - D-18057 Rostock = Germany - Tel +49 (0) 3812081 - 0 - Fax +49 (0) 3812081 - 202 - www.demogr.mpg.de

MPIDR Working Paper WP 2017-011 I May 2017

\title{
Urban and rural fertility transitions in the developing world: a cohort perspective
}

Mathias Lerch I lerch@demogr.mpg.de

This working paper has been approved for release by: Sebastian Klüsener (kluesener@demogr.mpg.de),

Deputy Head of the Laboratory of Fertility and Well-Being.

(C) Copyright is held by the authors.

Working papers of the Max Planck Institute for Demographic Research receive only limited review. Views or opinions expressed in working papers are attributable to the authors and do not necessarily reflect those of the Institute. 
Mathias Lerch

Research Scientist

Max Planck Institute for Demographic Research

Konrad-Zuse-Str. 1, 18057 Rostock - Germany

+49 (0)381 2081-179 (phone)

email: lerch@demogr.mpg.de

\title{
Urban and rural fertility transitions in the developing world: a cohort perspective
}

\author{
M athias Lerch
}

\begin{abstract}
Although the role of urbanization in fertility decline remains debated, few studies have assessed longterm fertility trends by urban/rural place of residence. Relying on successive surveys for 55 countries, we analyze the diffusion of cohort fertility decline in urban and rural areas across Africa, Asia and Latin America and the Caribbean. We show that, once the fertility transition is initiated, the decline in urban areas is similarly fast in all three continents. The pattern of the urban-to-rural diffusion of birth limitation, however, has differed significantly. In Latin American and Caribbean countries, the evolution in the rural-urban fertility differentials followed an inverted U-shaped pattern over the fertility transition. In Asia, the differences remained more limited, because of a parallel decline in fertility by type of place of residence, whereas in Africa they increased monotonically because rural areas have not yet experienced significant fertility declines. The implications of these results for urban population projections and for our understanding of the international variations in the pace of fertility transition are discussed.
\end{abstract}

Keyw ords: Cohort fertility, urbanization, urban-rural fertility differentials, developing countries 


\section{Urban and rural fertility transitions in the developing world: a cohort perspective}

\section{Introduction}

International assessments have not reveal patterned regularities in urban and rural fertility transitions beyond the universally earlier fertility decline in cities. This limits our ability to understand and project contemporary population change in a mainly urban world, in which the bulk of future increments is expected to be concentrated in cities. Even though urban growth is predominantly driven by the excess of the number of births over deaths, rather than by rural-to-urban migration (Chen et al. 1998; Christiaensen et al. 2013; Preston 1979), the United Nations urban - rural population projection methodology does not take account of these demographic components. Consequently, the information provided for planning is limited (i.e. only total population numbers) and tends to be over-projected (Bocquier 2005). The present study proposes a reappraisal of the patterns of urban and rural fertility change in the developing world to better inform future prospects.

Although the theory of the demographic transition intimately links the emergence of a small family ideal to the rise in urban and industrial living (Notestein 1953), the role of urbanization in fertility decline remains a matter of debate. Demographers of the structuralist school tend to consider rural-urban fertility differences merely as a spatial manifestation of the differential paces of structural changes of society (Galloway et al. 1998). When compared to rural areas, urban living increases the costs of childrearing. Cities offer also more avenues for socioeconomic mobility because of the rise of nonagricultural employment and the increased educational level of the population, thereby increasing the opportunity costs of fertility. Monetarized city economies are also more exposed to the negative fertility effects of financial crises. These structural forces of fertility decline are actually brought about and accelerated by population concentration, and may thus be considered as an integral part of the urban effect (Findlay 1980; Martine et al. 2013).

Scholars from the diffusionist school, by contrast, see rural-urban differentials in fertility as secondary manifestations within a system of homogeneous cultural regions among which fertility decline diffuses (Cleland and Wilson 1987; Coale 1973; Sharlin 1986). Yet the social context of urban areas accelerates the adoption of new reproductive behaviors. Cities interact more strongly with other world regions through social, economic and transport connections, which diffuse not only new reproductive behaviors but also the legitimacy of modern birth control from Western to less developed countries (Bongaarts and Watkins 1996; Caldwell 2001). Diffusion within urban areas is enhanced by the individualization and anonymization of society, which erodes old systems of social control, and by the denser social interaction and cultural diversification due to population concentration (Lesthaeghe 1980; Tabutin 
2000). Access to family planning services is also improved in cities when compared with the sparsely populated countryside (Findlay 1980; Martine et al. 2013). According to spatial diffusion theory, these new behaviors should then spread through a hierarchically and functionally structured settlement hierarchy into remote rural areas, via established communication and transport networks (Hägerstrand 1952; Klüsener et al. 2017). A re-assessment of urban and rural fertility trends in a fast urbanizing world should thus provide important insights into the spatial process of fertility change and help to predict future fertility developments at the national level.

Although the disaggregation of period total fertility rates (TFR) according to urban and rural place of residence is common practice in national demographic reports and regional syntheses, international evidence on temporal dynamics is scarce. In developing countries, cross-sectional analyses of ruralurban differentials in the TFR in the 1970s, as well as of short subsequent trends, points to a three-stage evolution over time (Findley 1978; Rodriguez 1996; Shapiro and Tambashe 2000; United Nations 1987). Starting from similar fertility levels by place of residence, the rural-urban difference increased sharply in the opening phase of the demographic transition due to an earlier and faster fertility decline in cities (see also Garenne (2002; 2008)). Later on, rural fertility levels tended to converge to the lower urban standard as the lagged decline in rural areas was also very marked. In Africa a slowing down of the decline in the urban TFR also contributed to the shrinking of rural-urban differential (Fargues 1988; Shapiro and Tambashe 2000). This is surprising, given that the pace of fertility transition is related to improvements in human development (Bongaarts and Watkins 1996; Bryant 2007), which characterized African cities throughout the second half of the $20^{\text {th }}$ Century (Kirk and Pillet 1998). The three-stage inverted U-shaped trend in the rural-urban differential, by contrast, is congruent with a centre-periphery diffusion of structural and behavioral change (Hägerstrand 1952). Although this pattern might be useful to inform prediction of future fertility developments, several issues preclude a general conclusion.

Whether rural fertility will converge with the urban standard in Africa remains to be seen, as the majority of countries are still in the early stage of their fertility transition. Rural-urban gradients remain substantial (i.e. one child or more per woman) not only in Africa, but also in the more advanced transition contexts of Asia and Latin America and the Caribbean (thereafter referred to as Latin America; Corker 2016; Montgomery et al. 2003). The present study covers a large geographical and temporal spectrum of fertility transitions to investigate the diffusion of fertility decline across urban and rural areas in 55 countries. We question whether the inverted U-shaped trend in the rural-urban fertility differential is confirmed from a long-term perspective in the three continents.

Previous international assessments of long-term fertility trends failed to identify patterned regularities by place of residence (Montgomery et al. 2003: 228). This has been related to the inability of the predominantly cross-sectional research approaches to account for international differences in context (M artine et al. 2013). Countries diverge not only in terms of the stages and quality of urbanization ${ }^{1}$, but also in terms of progress in the fertility transition. Moreover, the definition and delineation of urban

\footnotetext{
${ }^{1}$ The importance of slum areas, for example, varies significantly across countries. These urban environments may be less conducive to fertility decline when compared to more formal urban structures of society and labor markets.
} 
versus rural areas is country-specific, which is likely to bias international comparison. To control for this heterogeneity, we study average within-country trends in urban and rural fertility over the course of the national fertility transitions.

We believe that the lack of observed patterned regularities in long-term urban and rural fertility change is also due to the predominantly period perspective of previous research. Analysis of period fertility trends may mislead the assessment of the social and spatial diffusion of behavioral change because the TFR tends to be temporarily de- or inflated due to in-migration. In the 1990 s, between $16 \%$ and $32 \%$ of the urban populations in Latin American and Africa, respectively, were recent rural-to-urban migrants (M ontgomery et al. 2003). As such, they had been socialized to higher fertility norms in the countryside and were typically characterized by fertility levels intermediary between the rural and urban standards. Migrants' process of adaptation to lower urban fertility is generally completed only among their descendants, who have been socialized in cities (Brockerhoff 1998; Goldstein and Goldstein 1981; White et al. 2005). Moreover, an important part of the higher period fertility levels among migrants in urban areas can be explained by tempo effects. In order to facilitate relocation to cities, migrants tend to postpone births, which are then recuperated at the urban destination. As period indicators of fertility among in-migrants only measure the latter behavior, they tend to overestimate the intensity of childbearing (Toulemon 2004). The slowing down of the decline in urban period fertility in Africa (as observed by Shapiro et al. 2000) may thus have been caused by the arrival of more fertile women in cities.

To eliminate the disturbing effect of migration in the analysis of place-specific fertility changes over time, we focus on subsequent cohorts which have been socialized in the same type of place of residence (urban or rural) in which they continued to live during their reproductive life span. Situating women in the environment in which they learned norms and values about reproduction through education and exposure to behavioral patterns, enables us to properly analyze the role of socialization and structural change in the place-specific fertility declines. Comparison of the urban and rural trends then informs about the diffusion of the small family ideal across space.

The next section introduces the data and method used to analyze long-term cohort fertility change in urban and rural areas of 55 developing countries. We then describe trends in urban fertility, and evaluate the hypothesis of an inverted U-shaped evolution of the rural-urban differential in Africa, Asia and Latin America. The underlying differences between continents in terms of the pace of fertility decline by place of residence are documented as well. Results reveal that, once the fertility transition is initiated, the decline in urban areas is similarly fast in the three continents. The patterns of urban-torural diffusion of birth limitation, however, differed significantly. The inverted U-shaped evolution in the rural-urban fertility differetial over time was only confirmed in Latin American countries. In Asia, the gradients remained more limited, whereas in Africa they increased monotonically. The implications of these results for urban and rural population projections and our understanding of the international variation in the pace of fertility transitions are also discussed. 


\section{Data and analytical strategy}

We adopt a cohort approach to fertility and focus on the non-migrant population in order to better appreciate the diffusion of fertility decline in urban and rural areas, as driven by structural and ideational changes in society over time.

\section{Data}

The focus is on fertility of successive cohorts which have been socialized in urban or rural areas and did not move to another type of place of residence during their childbearing ages. This study population was identified based on 146 World Fertility Surveys (WFS) and Demographic and Health Surveys (DHS) for 55 developing countries (with 1 to 10 surveys per country; see Table 2 in Appendix). The surveys interviewed reproductive-age women, who have been selected according to a classic two-stage clustered sampling design, and collected information on the number of children ever born (i.e. parity) and the full birth histories. To increase the geographic coverage of this study, we also included those surveys which only interviewed ever-married women. At the ages at which we measure cohort fertility (age 30 and above), the overwhelming majority of women were or had been married in our sample of countries. The cross-validation of our estimates did not reveal significant biases (see Appendix).

We excluded countries from the former Soviet Union, small island countries, and countries for which the survey did not provide information on urban-rural migration. Our final sample of countries is classified by continent according to the United Nations typology and covers the whole spectrum of urbanization. According to the United Nations, in the average African and Asian country 33\% of inhabitants lived in urban areas in 2000, with a minimum of $8 \%$ in Burundi and $13 \%$ in Nepal and a maximum of $80 \%$ in Gabon and Jordan (see Table 2 in Appendix). In Latin America, the average country counts $61 \%$ of its population in cities, with a range between $36 \%$ in Haiti and $81 \%$ in Brazil.

The urban/rural status was recorded for the current and childhood (or previous) place of residence (alongside the date of the last move; see Appendix). Unfortunately there is no harmonized definition of urban and rural areas across space and time. The urban/rural status at the survey date is defined according to national standards, which diverge significantly. National definitions may also change over time, and the boundaries tend to move out into formerly rural areas as urban populations sprawl. The urban/rural status of the previous residence is self-reported, and thus subject to even larger biases. However, the responses reflect women's perception of the environment of socialization, which is relevant for analyzing the diffusion of cohort fertility change. As the urban and rural fertility trends estimated on the basis of subsequent surveys within a given country align (see Appendix), we rule out the possibility of major analytical biases.

To avoid the disturbing effects of in-migration on place-specific fertility trends, we excluded migrants who crossed an urban-rural boundary after childhood (or reaching age 15), whereas their non-migrant descendants are included. The population of migrants represented $22 \%$ of the interviewed women aged 30 or more in the average country, with a first percentile of $10 \%$ and a ninth percentile of $34 \%$. Their exclusion evidently slightly increased the rural-urban fertility differential - especially in the least and the most urbanized countries (see Appendix). In order to evaluate the bias of migration in the assessment of 
the diffusion of fertility decline in urban areas, we also replicated the analysis on a sample including all women classified according to their place of residence at the survey date (rather than at childhood).

\section{Method}

Total cohort fertility (TF) is measured here based primarily on parity data. We use cohort parityprogression ratios (PPR) which measure the proportion of women who have already had a given number of children going on to have an additional one ${ }^{2}$. The level of TF is estimated as a weighted average of the parities attained, with the weights being the parity distribution of women as implied by the chaining of the progression ratios from nulliparous to the first parity (PPR1) to the progression from the fifth to the sixth parity (PPR6). For the last parity group (women with at least six births), the attained parity was estimated as the average number of children ever born to this group at the survey date; inter-survey figures have been interpolated.

For the five-year age cohorts that have completed their childbearing career at the time of the interview (i.e., aged 40-44 and 45-49), we use the distribution of women according to the reported number of children ever born (i.e. parity) to directly estimate PPRs. Estimates for age cohorts with fewer than 60 women are discarded. In order to fill inter-cohort estimation gaps and extend the series with more recent cohorts, we estimated truncated PPRs of the cohorts aged 30-34 and 35-39 at the survey dates and projected the completed PPRs at age 40-44.

The Brass-Juarez paired cohort comparison procedure was applied (Brass and Juarez 1983; Moultrie et al. 2012). The incomplete PPRs for younger age cohorts are projected forward by adjusting the completed PPRs of the cohort aged 40-44 for the fertility trends between adjacent (younger) cohorts as observed in the most recent period: the completed PPRs of the cohort aged 40-44 are multiplied by that cohort's fertility differential with the immediately younger cohort, the latter cohort's fertility differential with the subsequent cohort, etc. In other words, the completed PPRs are multiplied with the downwardcumulated fertility change ratios between successive pairs of adjacent cohorts. Fertility change ratios are estimated at equivalent ages and parities in order to control for the selection of more fertile women in parity groups at lower ages: by subtracting recent births (as reported in the birth histories) from the reported number of children ever born to older cohorts, their PPRs are truncated five years before the survey in order to ensure comparability with the younger age cohort's similarly truncated PPRs at the survey date.

The method assumes that the recent fertility differentials between adjacent cohorts stay constant in the second half of the reproductive career (recuperation of births which have been forgone at younger ages is assumed to be completed in the thirties, and no further differential postponement is allowed between adjacent cohorts). These assumptions are reasonable, as few countries in our sample experienced a

\footnotetext{
${ }^{2}$ (Truncated) cohort fertility could also be estimated based on age-specific birth rates relying on information in the birth histories. As the quality of the reporting of birth events in the period immediately preceding the surveys is problematic in several countries (Schoumaker, B. 2014. Quality and Consistency of DHS Fertility Estimates, 1990 to 2012. DHS M ethodological Reports 12:122.), we decided to rely primarily on parity data.
} 
strong postponement of first births, and the delay of higher order births has only limited tempo effects. Survey weights were applied.

The inclusion of the projections for younger cohorts based on an earlier survey also enables us to crossvalidate the quality of the data on children ever born at older ages (as reported at a subsequent survey), which can be problematic due to recall biases and sample selection biases related to past mortality and migration (M oultrie et al. 2013; United Nations 1983). The results of this internal plausibility test of the PPRs confirmed the high quality of the data (see Appendix). Before estimating annual series of TF, we thus averaged the PPRs obtained from successive surveys for overlapping 5-year age cohorts, annually interpolated the figures and smoothed the country-specific series by place of residence. We also estimated the national-level TF for the whole sample (including migrants) and compared the trends with estimates of the cohort total fertility rate (CTFR) based on DHS birth histories for Africa (Sneeringer 2009), and with back-translated period estimates of the TFR from the United Nations. These external plausibility tests confirmed the accuracy of our estimates based on parity data - even in countries where only ever-married women have been interviewed (see Appendix).

As our series cover cohorts born between 1926 and 1978, we observe at least the early to intermediate stages of the national fertility transitions in the majority of countries - especially in Asia and Latin America (see Table 1 and Fig. 5 in Appendix). Fertility of cohorts born after 1978 and which have been socialized in a similar urban or rural environment to the current place of residence cannot be estimated, because the retrospective questions about migration and the previous place of residence have been excluded from the recent waves of the DHS. The average country contributes with 25 single-year birth cohorts, with a range from 10 cohorts (i.e., countries with only one survey) to 50 cohorts (i.e., ten surveys).

\section{Analytical strategy}

To control for the different stages attained by each country in the fertility transition, trends are analyzed by cohort-years relative to the onset of the national fertility transition. We defined the onset of the transition as the calendar year in which the TFR peaked last before the first 10\%-decline (following Casterline (2001)), using the United Nations' historical and World Population Prospects estimations of the TFR for five-year periods which we annually interpolated with a linear function. The calendar year of the onset was then back-translated by 30 years (i.e. the mean age at birth) to get a cohort indicator.

We are unable to estimate trends by continent because of the lack of (extended) series for the world's demographic giants (such as China, Argentina, Nigeria, Brazil, India). Instead we summarized trends following the approach of Casterline $\&$ Odden (2016). Using linear spline regression models stratified by rural and urban areas and continent, we estimated the pace of cohort fertility change over time (with knots at the onset of the transition and 10,20 and 40 cohorts later). The coefficients were then used to predict average trends. Models are estimated with country fixed effects in order to control for the unobserved heterogeneity in the national contexts of urbanization. The focus is thus on average urban and rural fertility trends of individual countries by continent. Single country series are also shown in order to appreciate intercountry variations and to identify atypical trends. 


\section{Results}

\section{Urban fertility transition}

Figure 1 shows the urban trends in cohort fertility within the time-frame of the national fertility transitions. In Latin America and Asia, we observe only a few pre-transitional cohorts. Urban fertility was either declining sharply or was already below 6 children per woman. In Africa, the pre-transitional declines were less marked, with an average fertility above 6 . There was even a slight pre-transitional increase in urban fertility in some countries, which can be related to improved health and the abandonment of traditional practices of birth regulation (such as sexual abstinence and prolonged breastfeeding) in the early stages of modernization (Dyson and Murphy 1985). Average cohort fertility fell from 6 to 2.5 children over the first 40 transitional cohorts in all three continents.

Figure 1: Average and country-specific trends in urban cohort fertility over the course of the national fertility transitions (onset =year 0), cohorts 1925-1978 in African, Asian and Latin American countries.

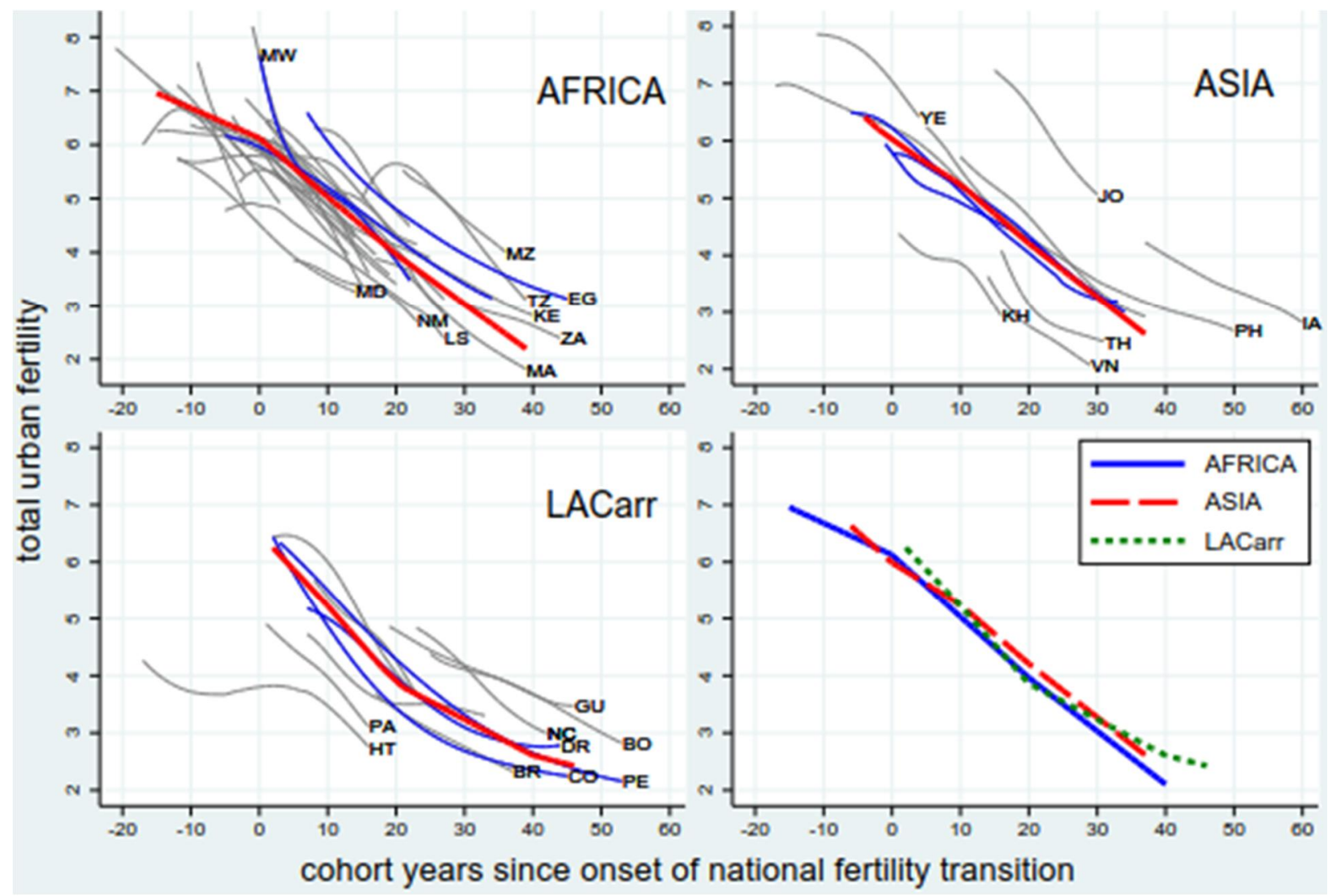

Source: WFS \& DHS.

Notes: thick lines designate average within-country trends; fine blue lines designate countries with long estimations series; LACarr = Latin America and the Caribbean; see Table 2 in Appendix for country acronyms; the onset of the transition corresponds to the calendar year in which the TFR peaked, which was then back-translated by 30 years to get a cohort indicator. 
During the transition, urban fertility declined continuously at a fast pace in all continents. In Latin America, the average decline leveled off among the cohorts born approximately 30 years after the transition onset (when fertility tended to be below 3). In Africa and Asia, however, the decline was monotonic until the last observed cohorts. A slowing down of the urban fertility transition is only observed in Thailand, the Philippines, South Africa and Egypt - even though urban fertility crossed the threshold of three children per woman in many more countries.

Although the onset of the urban, relative to the national, fertility transition diverged across countries, the results point to a strong similarity in the average paces of decline by continent once the transition started. These average within-country trends by continent are not biased by our unbalanced set of country-specific time-series, as they are confirmed by trends in countries with long data series (in blue).

\section{Diffusion of fertility limitation to rural areas}

We now turn to the diffusion of the new limiting behaviors from urban to rural areas. Figure 2 shows the trend in the rural-urban cohort fertility ratios over the course of the national fertility transitions. If urban and rural fertility declined at the same time and pace, countries would align on the dashed horizontal line at unity (drawn in red). Lines situated above (below) that reference line indicate higher (lower) rural fertility, relative to the urban level in a given cohort. We computed the rural-urban ratio, rather than the difference, because it provides us with a standardized measure of the differential over the course of the fertility transition ${ }^{3}$.

As urban fertility probably started to decline before the onset of the national transitions in Latin America, the rural-urban ratio was already situated above unity among the onset cohorts in several countries. The ratio further increased sharply in the first twenty transition cohorts (by 0.03 rural excess children per cohort on average), following which the trend flattened out at a high 1.7 (when the urban TF reached levels below three children). Although the average trend remained constant later on, more than half of our 12 Latin American countries in the sample experienced a decline in the fertility ratio among the most recent transitional cohorts (Brazil, Peru, Dominican Rep., Nicaragua, Guyana, and to a lesser extent, Bolivia and Columbia). Only Haiti is a clear outlier with an uninterrupted steep increase in rural excess fertility even after urban fertility fell below 3. Thus, Latin America provides support to the hypothesized inverted U-shape trend in the fertility ratio by place of residence, even though the most recent cohorts observed in our data only confirm the beginning of the right-hand descending tail of the curve.

\footnotetext{
${ }^{3}$ Results based on the rural-urban differences are qualitatively the same, although the differentials shrink to a larger extent in later stages of the fertility transitions (not shown).
} 
Figure 2: Average and country-specific trends in the rural-urban cohort fertility ratio over the course of the national fertility transitions (onset =year 0), cohorts 1925-1978 in African, Asian and Latin American countries

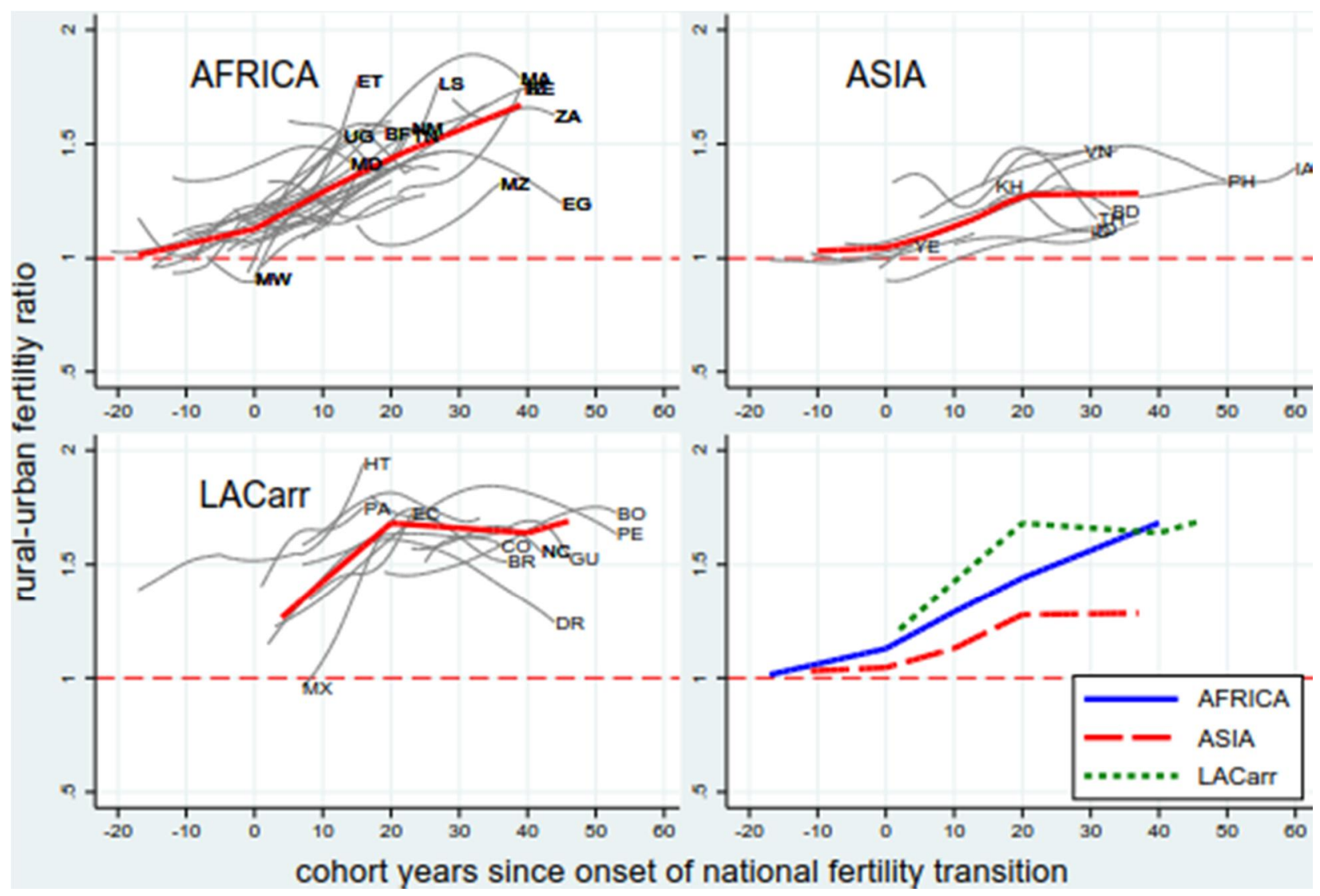

Source: WFS \& DHS.

Notes: thick lines designate average within-country trends; fine blue lines designate countries with long estimations series; LACarr = Latin America and the Caribbean; see Table 2 in Appendix for country acronyms; the onset of the transition corresponds to the calendar year in which the TFR peaked, which was then back-translated by 30 years to get a cohort indicator.

In Africa, the average rural-urban ratio in cohort fertility increased less steeply but monotonically during the fertility transition (by 0.01 to 0.02 excess children per cohort). The ratio increased from unity among cohorts born 10 years before the transition onset, to more than 1.5 forty cohorts later (when urban fertility was below 3). Although there is significant inter-country variation in the level of excess rural fertility - with smaller gradients in the least urbanized countries of Sudan, Burundi, Cameroon and Rwanda - the trends were similar across the continent, especially in the early stages of the transitions. A significant decrease in the rural-urban fertility gradient in the late stages of the transition was observed only in North Africa (i.e. in Egypt and, more timidly, in Morocco). In several other countries, the ratio continued to increase in the advanced stages of the transition (for example in Kenya, Ethiopia and Lesotho). 
The Asian continent stands out with a lower average rural-urban fertility ratio over the whole transition period. Starting from a ratio at unity in the onset cohort, the average rural excess fertility increased only slightly among the first 10 transition cohorts (by 0.01 births per cohort). The trend accelerated somewhat to reach a maximum ratio of 1.3 among the cohorts born 20 years after the onset of the fertility transition. This was followed by a stabilization of the fertility differential, similar to the trend in Latin America. Only four out of 12 countries in our Asian sample experienced a decline in rural excess fertility among the most recent transition cohorts (in Thailand and, to a lesser extent, in Bangladesh, Jordan, and the Philippines).

In contrast to the similarity in the urban fertility declines across continents, the results reveal a significant international diversity in the diffusion of birth limitation to the countryside. As in the case of the urban fertility trend, the evolutions in the rural-urban fertility ratios in countries with long data series (not shown) confirm the average trends by continent.

\section{The pace of urban and rural fertility change}

To better understand the continental differences in terms of the diffusion of fertility decline from urban to rural areas, Figure 3 shows the annual average within-country pace of decline in urban and rural cohort fertility over the course of the national fertility transitions by continent. Inter-country interquartile ranges of the paces of decline (as estimated using country-specific linear spline regression models) are also given for successive stages of the transition by continent (Table 1). We interpret an increasing variation as a diversification of the onsets and paces of fertility decline (in early and later stages of the transition, respectively), whereas a decreasing interquartile range indicates a convergence of country-specific trends.

In Latin America, the high rural-urban fertility ratio at the start of the transition, as well as the sharp increase in the first transition decade, can be explained by a steeper fertility decline in urban when compared to rural areas (on average -0.13 and -0.07 to -0.09 children per cohort, respectively). The inter-country variation in the urban declines was highest in the early stage of the transition, with an interquartile range of 0.12 children per cohort. The interquartile range then shrank as an increasing number of countries followed the fast declining urban fertility trend. The catch up of this trend in the countryside started only in the second transition decade, as revealed by the peak in inter-country variation in the rural paces of fertility change ( 0.16 children per cohort). Yet the average rate of the rural decline never reached the urban trough.

The stabilization of the Latin American rural-urban fertility gradient in the advanced stage of the transition, by contrast, resulted from two different processes. On the one hand, there was a cross-over of the urban and rural paces of fertility decline among cohorts born twenty to forty years after the transition onset. The average rate of decline in urban areas slowed down to -0.06 children per cohort with small inter-country variation. The average rural drop, by contrast, became more pronounced (above -0.1 children per cohort). This trend also concerned an increasing number of countries, as revealed by the decline in the interquartile range. On the other hand, among cohorts born 40 years after the transition onset, the rural pace of decline slowed down and converged to the less steep urban pace, although with larger inter-country variations. Thus, the temporal sequencing of fertility decline over 
time was similar in both places, but the rural trend lagged behind the urban trend by about two decades. Latin American countries followed the pattern of rural-urban period fertility differentials revealed by Shapiro \& Tambashe (2000) in Africa.

Figure 3: Annual average pace of fertility decline in urban and rural areas over the course of the national fertility transitions (onset =year 0), cohorts 1925-1978 in African, Asian and Latin American countries

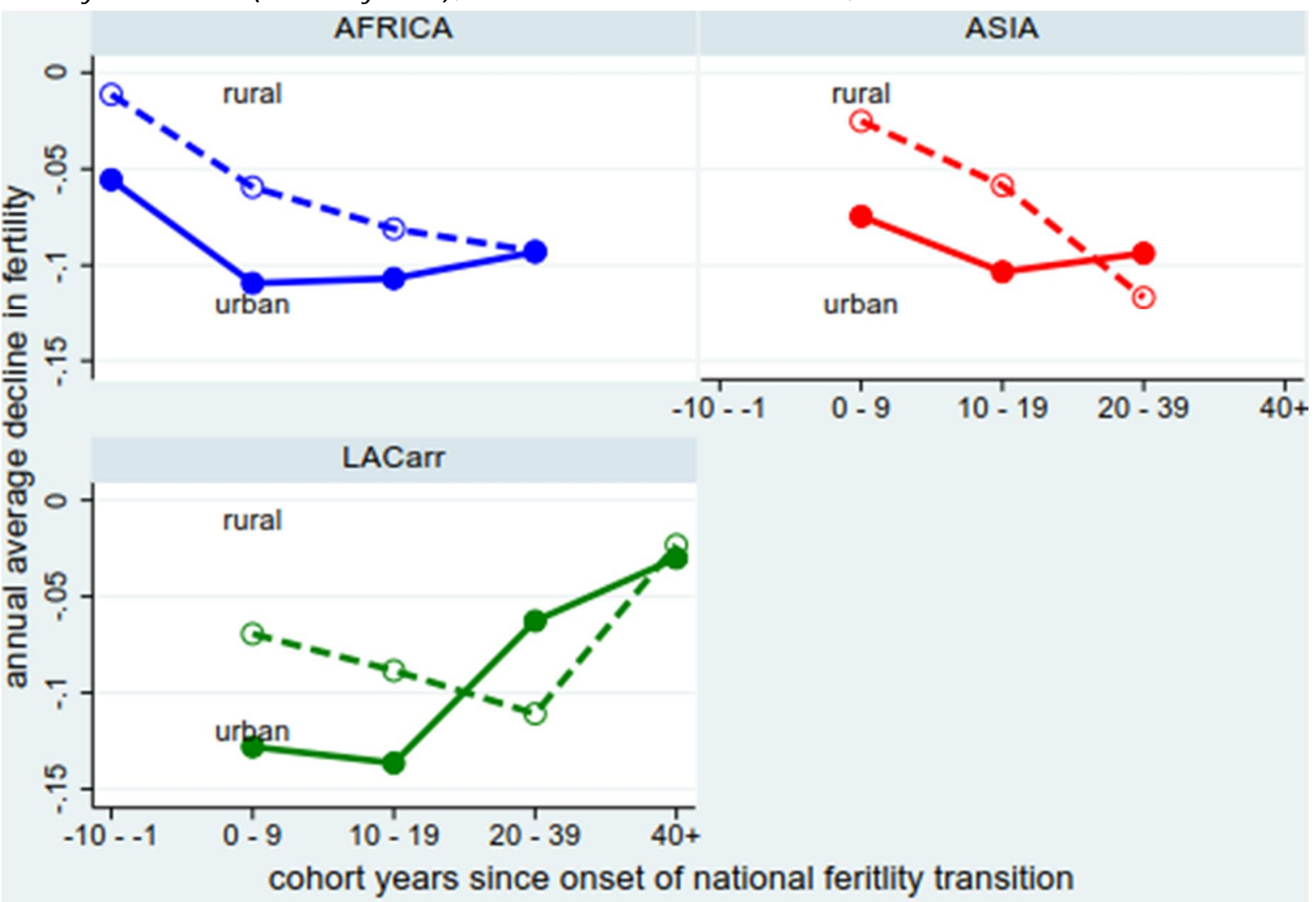

Sources: DHS\& WFS. Note: LACarr =Latin America and the Caribbean. 
Table 1: Inter-country interquartile range in annual average paces of cohort fertility decline over the course of the national fertility transitions, cohorts 1925-1978 in urban and rural areas of African, Asian and Latin American countries

\begin{tabular}{|l|l|l|l|}
\hline \multirow{2}{*}{ Continent } & $\begin{array}{l}\text { Cohort years } \\
\text { since the } \\
\text { transition }\end{array}$ & \multicolumn{2}{|l|}{$\begin{array}{l}\text { Interquartile range in } \\
\text { paces of fertility decline }\end{array}$} \\
\cline { 2 - 4 } & onset & urban & rural \\
\hline AFRICA & 1st 10y & 0.08 & 0.06 \\
& 2nd 10y & 0.06 & 0.08 \\
& later 20y & 0.07 & 0.09 \\
\hline ASIA & 1st 10y & 0.10 & 0.11 \\
& 2nd 10y & 0.03 & 0.06 \\
& later 20y & 0.04 & 0.03 \\
\hline LACarr & 1st 10y & 0.12 & 0.05 \\
& 2nd 10y & 0.04 & 0.16 \\
& later 20y & 0.03 & 0.09 \\
\hline
\end{tabular}

Sources: DHS \& WFS

In Africa, the rural-urban fertility ratio did not stabilize in the advanced transitional stages because there was no cross-over in the paces of fertility decline by place of residence. In the first two transitional decades, the average pace of the urban decline was only slightly less pronounced than that observed in Latin America (more than -0.1 births per cohort). The rural pace of decline was less steep ( -0.06 to -0.08 births per cohort), but comparable to the experiences in the Latin American countryside. Among cohorts born 20 years after the transition onset, the African pace of urban fertility decline stabilized rather than slowing down. The slower rural pace continued to accelerate only slightly. Instead of an urban-rural cross-over in the paces of fertility declines, they just converged. M oreover, the stronger decline in urban areas at the start of the transition, as well as the later acceleration of the process in rural areas, was more widespread (e.g. synchronized) among African countries when compared to Latin America, as indicated by the smaller respective interquartile ranges in the country-specific paces of decline.

The limited rural-urban fertility ratio in Asia can be explained by both a more parallel and a more progressive trend in the average paces of fertility decline by place of residence, when compared to the patterns observed in the other two continents. The average urban pace accelerated from -0.07 children per cohort in the initial transition period to -0.11 children in the second decade. As the rural pace of decline also increased from -0.03 to -0.07 , the increase in the rural-urban fertility ratio remained limited. Among cohorts born 20 years after the transition onset, in urban areas the average pace of fertility change stabilized rather than slowing down, whereas in rural areas it accelerated strongly to reach slightly steeper levels than in urban areas (-0.11 children per cohort). Thus the Asian rural-urban fertility ratio stabilized rather than decreased in the late transitional stages because of a limited cross-over of the place-specific paces of fertility decline, when compared to Latin America. The fertility differential remained limited overall because the urban and rural onsets of, and trends in, fertility decline appear to have been synchronized over the course of the national transitions. This is indicated by the evolution in 
the inter-country variations in fertility change among urban and rural areas of Asia: they were similarly high during the first transition decade, and declined to comparable levels in later stages of the transition

- although the inter-country convergence with regard to the pace of fertility decline was faster among urban areas.

\section{Discussion and conclusion}

Evidence about the speed of urban fertility decline and about its diffusion to the countryside in developing countries is crucial to predict population change in urban and rural areas, as well as future fertility developments at the national level. We aimed to overcome two challenges in previous research to identify patterned international regularities in the long-term diffusion of birth limitation by type of place of residence. Relying on multiple surveys for 55 countries, we analyzed fertility trends over cohorts which were socialized in the same type of place of residence as the one in which they resided during their childbearing ages, in order to eliminate the perturbing effect of migration. To control for international differences in terms of urbanization and demographic context, we focused on average within-country trends in levels and rural-urban gradients over the course of the national fertility transitions.

The results revealed an impressive similarity between continents in terms of the fast pace of urban fertility decline. Average fertility dropped to near replacement levels after only 40 years since the national transition onset in the three continents. The only marked difference concerned Latin America, where the urban fertility decline leveled off in the late stages of the transition. This may be explained by familistic values in society and the early onset of the fertility transitions on this continent, in a period when low fertility was not yet widespread worldwide. In Africa, which was the latest to engage in the fertility transition, low fertility spread rapidly into the continent's cities. But in African countries, a leveling off in the urban fertility decline proves to be the exception. This contradiction of our cohortspecific results with Shapiro and Tambeshe's (2000) period observations of a slowing down in the urban fertility transitions in Africa highlights the role played by the socialization of urban in-migrants to rural standards of childbearing. Our robustness tests (see Appendix) confirmed that in-migrants inflated the fertility level on average by 0.5 children in urban Africa, an effect that reaches up to one child in Western Africa which is the least advanced region in the fertility transition. In the more urbanized Latin American context, by contrast, in-migrants had a limited impact on the urban fertility estimates (which are inflated by only 0.25 children). In Asia, the migration effect on urban fertility is similarly low. In addition to smaller rural-urban fertility gradients, migrants may also be selected to a larger extent among less fertile women in rural areas of this continent.

The common pattern of urban fertility decline across continents confirms the idea that the fertility transition is a consequence of an universal process of structural and ideational change of society that accompanies economic development, and which is intimately related to, and intensified by, population concentration in cities. Although sub-Saharan Africa is often believed to follow a different path of fertility transition, this does not apply to the regions' cities. This universally fast urban fertility decline implies that we can confidently predict long-term urban fertility trends. (Forecasting medium-term fluctuations would require additional country-specific evidence about the interactions between in- 
migration and fertility.) Thus, more disaggregated projection methodologies can be implemented in order to account specifically for the demographic components of urban population change. This has the potential to provide improved forecasts and, more certainly, more policy-relevant information (on urban age-structures and the numbers of births, deaths and migrations).

The fast decline in urban fertility across all three continents contrasts with significant variation in the pace of progress in national-level fertility transitions (Casterline 2001). Our results suggest that this international heterogeneity is primarily driven by variations between countries in the diffusion of birth limiting behaviors from cities to the countryside (in addition to differential paces of population urbanization). Rural fertility decline lagged far behind the urban trend in Africa, less markedly in Latin America, and was almost synchronized with it in Asia. The peak pace in rural fertility decline over the first 40 transition cohorts was also slowest in Africa. In Latin America, by contrast, it surpassed the urban rate in the late stages of the transition. These differences resulted in distinct patterned evolutions of the rural-urban fertility differentials by continent. Although the average difference increased at a fast pace to high levels in Latin America, rural fertility tended to converge to the lower urban standard in late stages of the transition in several countries. The Asian rural-urban fertility differential only rose to a limited extent and stabilized thereafter, whereas in Africa it increased monotonically over time. Ruralurban fertility convergence was observed in a limited number of countries in Asia, and in only two North-African countries.

The model of a lagged spatial diffusion of fertility change, which was suggested by cross-sectional studies and explained theoretically by urban-rural lags in structural and ideational transformations of society, therefore applied in practice mainly in Latin American countries. Given the aggregate nature of the results presented in this study, we can only speculate about the reasons for these differences between continents. Lower levels of urbanization may limit social interaction with the countryside and thus slow down the spatial diffusion of birth limitation. But this interpretation is challenged by a faster urban-to-rural diffusion of fertility decline in Asia when compared to Africa, even though both continents are much less urbanized than Latin America. The parallel urban and rural fertility declines in Asia may be related to authoritative family planning policies which enforced birth limiting behaviors in the countryside. Another explanation may be the existence of strong social interactions between rural and urban societies, which speed up the diffusion of behavioral changes from urban areas. Moreover, the formerly communist countries in Asia experienced a fast fertility transition, while the urbanization process was restrained by governments. Limited rural-urban fertility gradients may here simply indicate a loose relationship between the transformations in socioeconomic structures of urban and rural populations and their respective levels of fertility.

The continuously increasing rural-urban fertility differential in Sub-Saharan Africa, by contrast, may be explained by the region's distinctive context of fertility decline (Bongaarts 2016). As the transitions started at lower levels and at slower paces of economic growth, the spatial diffusion to rural areas of structural transformations in society may be slower, thereby inhibiting socioeconomic incentives for birth limitation. The limited availability of, and the difficult access to, family planning services in the countryside has probably also played a role. Moreover, these fertility transitions started in more recent periods of globalization. African rural areas may be particularly isolated from the modern lifestyles 
diffused into cities which are better connected to the global community. This fracture between urban and rural societies may inhibit spatial diffusion mechanisms. Another related explanation suggests distinct patterns of fertility transitions in rural and urban areas. Recent studies have identified the subSaharan fertility decline as a distinct process which was driven by the spacing or postponement of all higher order births, rather than by a stopping behavior of childbearing once the desired family size has been reached (Caldwell et al. 1992; Johnson-Hanks 2007; Moultrie et al. 2012). This pattern implies a slow cohort fertility decline that essentially involves higher parity groups, as women end up with insufficient reproductive years left to achieve large family sizes. Our results suggest that this pattern holds only for rural areas of this world region. Future research on the parity-specific patterns and socioeconomic correlates of fertility decline would be helpful to increase our understanding of this international variation in terms of changes in childbearing across urban and rural areas, and to better inform future population and fertility projections.

\section{Appendix: Data, cross-validation of cohort fertility estimates and projections, and robustness checks}

The sample of countries by continent is listed in Table 2, alongside the survey waves used, the cohorts covered by the data, as well as the first and last cohort fertility estimates by place of residence.

The WFS collected information on the urban/rural status of the "childhood place of residence" without information on the date of the last move. The DHS surveys used here collected information on duration of residence in the current location or the age at the last move, alongside the urban status of the previous residence. We assumed that women moved only once (at most) since childhood and harmonized the information with that provided in the WFS by identifying women who did not move across urban/rural borders after age 15 .

To assess the quality of parity reporting among older women and the accuracy of our projections for younger cohorts, we cross-validated the observed and projected values of completed PPRs for overlapping cohorts as obtained respectively from two successive surveys. We found a higher agreement between observed and projected PPRs in rural areas and at lower parities, which can be explained by larger samples of women when compared to urban areas and higher parity groups. Figure 4 shows the most problematic crude series of observed and projected progression ratios - i.e. the transition to the sixth birth (PPR6) for urban areas - in a selection of countries, as obtained from successive surveys (in blue), as well as the average, annualized and smoothed trend (in red). On each individual blue line, the last two points designate projected values, whereas prior points represent estimates.

In urban Bangladesh, the Philippines, Indonesia and Peru, the series almost perfectly overlap. Yet recent projection points from the penultimate surveys tend to be higher when compared with figures based on both the preceding and following surveys. This may have arisen because of different sample compositions. The examples of Togo, Vietnam and Kenya illustrate the (rare) worst cases in terms of the disagreement between estimated and projected PPRs. In Vietnam, the projections based on the first survey are higher when compared with the estimates from the second survey. Younger birth cohorts 
may have shortened birth intervals (relative to older cohorts) at younger ages, but were not more likely to progress to the sixth birth (as assumed by the chaining of inter-cohort fertility change ratios in the Brass-Juarez method). Alternatively, parity may have been under-reported among older women at the second survey. In urban Togo, the projected PPR6 from the first survey are significantly lower when compared to the estimated value based on the second survey. This may point to a sample selection bias of more fertile women at the second survey. In urban Kenya, several biases may interact to produce the most erratic pattern observed in our sample of countries.

Figure 4: Survey-specific estimated and projected transition ratios to the $6^{\text {th }}$ parity (in blue; PPR6) and the average, annualized and smoothed trend (in red) in urban areas of selected countries, cohorts 1926-1978 in Asian, Latin American and African countries.

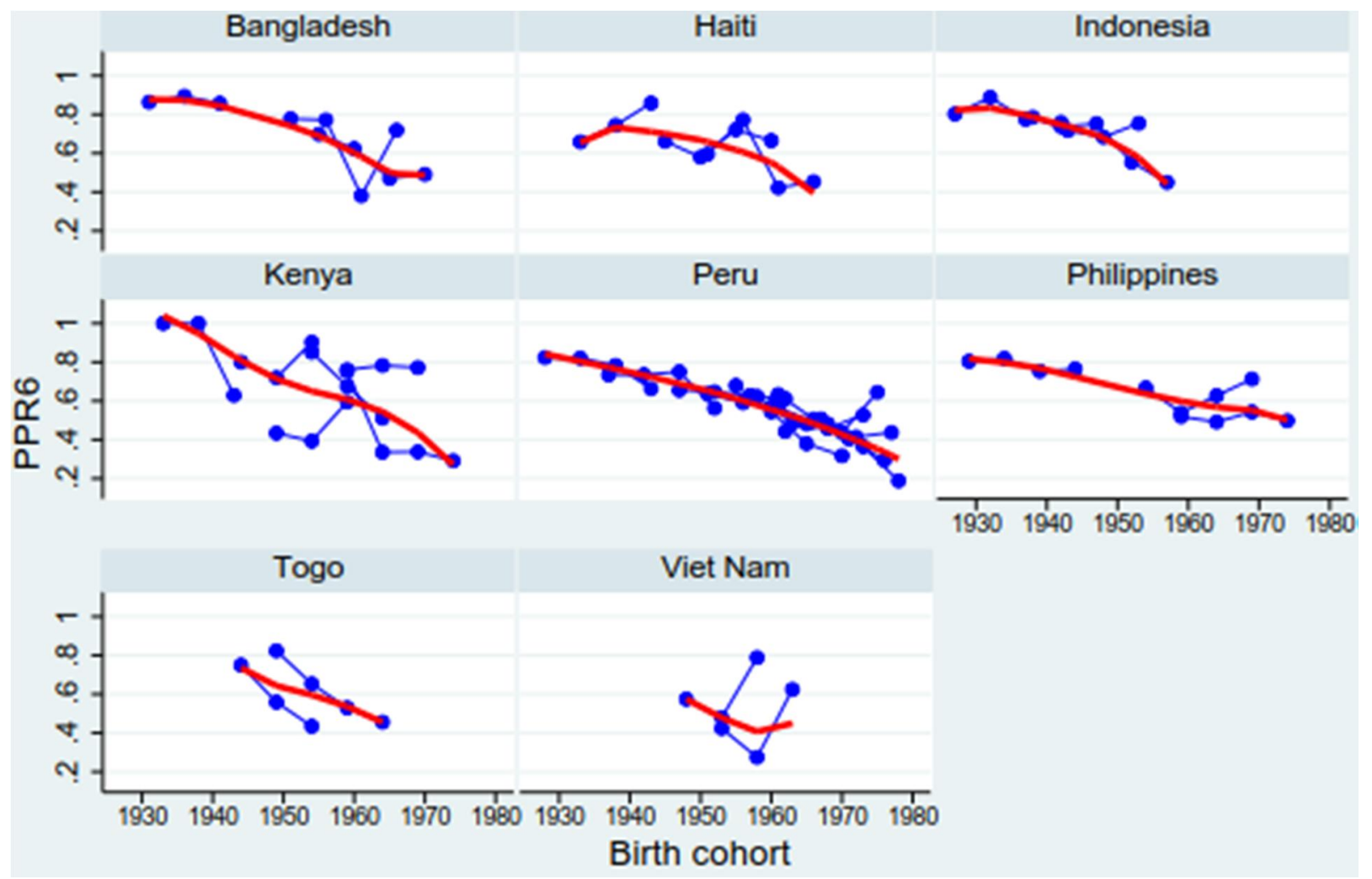

Source: DHS \& WHS.

Notes: The survey-specific estimates and projections of lower parity transitions, and in rural areas, are not shown as they are very congruent to each other.

The quality of the estimates is generally more problematic in the poorest countries within each continent. In these cases, not only the parity data may be of poorer quality, but also the forecast accuracy may be lower because of the underreporting of recent births (Schoumaker 2014), which leads to a mis-estimation of inter-cohort fertility changes used to project forward the truncated PPRs. Alternatively, the survey samples may not well represent the population due to sampling, migration and mortality-related selection biases. 
Overall, however, the quality of our estimates and projections of completed PPRs is good. We thus annually interpolated our series for 5-year cohorts and smoothed the trend by, first, averaging data points for overlapping cohorts and, then, applying a running line function (using the locally weighted least squares technique; see thick lines in Fig. 4). Survey weights are applied. We chained these smoothed PPRs to estimate the parity distribution of cohorts, which constitutes the weights to estimate the total cohort fertility (TF) as implied by a weighted average of the parities attained.

As an additional quality check, we estimated national-level total cohort fertility (including migrants) based on the PPRs (which are primarily based on parity data) with two external estimates: the United Nations' TFR series which have been back-translated by 30 years (i.e. the average age at childbearing in high fertility contexts), and Sneeringer's (2009) estimates of the total cohort fertility rates (CTFR) based on the pooled birth histories from successive DHS surveys in Africa. As shown in Fig. 5, our estimates fit the two other series well. The levels of cohort fertility diverge in Yemen and Haiti, but the trends are congruent. For some African countries, however, our parity-based estimates tend to indicate an earlier fertility decline than the UN series. This may be explained by a higher mean age at birth, which confounds the comparison with the back-translated TFRs. The CTFR based on the birth histories is situated either between our parity-based and the UN estimates, or are closer to our figures. In Chad, Burkina Faso, and Niger, however, we tend to under-estimate fertility among the most recent cohorts. 
Table 2: Country-specific levels of urbanization, number and dates of fertility surveys, observed 5-year age cohorts, and urban and rural estimates of cohort fertility in African, Asian and Latin American countries.

\begin{tabular}{|c|c|c|c|c|c|c|c|c|c|c|c|c|c|c|c|c|c|c|c|}
\hline \multirow[b]{3}{*}{ AFRICA } & \multirow{3}{*}{$\begin{array}{l}\text { Country name } \\
\text { Benin }\end{array}$} & \multirow{3}{*}{$\begin{array}{l}\text { Acronym } \\
\text { BJ }\end{array}$} & \multicolumn{2}{|c|}{$\%$ urban } & \multirow{3}{*}{$\begin{array}{l}\mathrm{N} \text { of } \\
\text { surveys } \\
4\end{array}$} & \multicolumn{6}{|c|}{ Survey years } & \multicolumn{4}{|c|}{ Urban cohort estimates } & \multicolumn{4}{|c|}{ Rural cohort estimates } \\
\hline & & & $\begin{array}{l}1950 \\
\text { (UN) }\end{array}$ & 2000 & & 1st & 2nd & $3 r d$ & 4th & 5th & 6th & $\begin{array}{l}\text { Start } \\
\text { Year }\end{array}$ & TF & $\begin{array}{l}\text { End } \\
\text { Year }\end{array}$ & TF & $\begin{array}{l}\text { Start } \\
\text { Year }\end{array}$ & TF & $\begin{array}{l}\text { End } \\
\text { Year }\end{array}$ & TF \\
\hline & & & 5.0 & 38.3 & & 1981 & 1996 & 2001 & 2006 & & & 1937 & 5.8 & 1972 & 4.1 & 1932 & 6.4 & 1972 & 5.8 \\
\hline AFRICA & Burkina Faso & $\mathrm{BF}$ & 3.8 & 17.8 & 2 & 1992 & 2003 & & & & & 1948 & 6.3 & 1969 & 3.6 & 1943 & 7.8 & 1969 & 5.6 \\
\hline AFRICA & Burundi & BU & 1.7 & 8.2 & 1 & 1987 & & & & & & 1943 & 7.1 & 1953 & 4.9 & 1938 & 7.3 & 1953 & 5.7 \\
\hline AFRICA & Cameroon & $\mathrm{CM}$ & 9.3 & 45.5 & 2 & 1991 & 1998 & & & & & 1947 & 5.3 & 1964 & 4.3 & 1942 & 6.4 & 1964 & 5.4 \\
\hline AFRICA & Chad & TD & 4.5 & 21.6 & 1 & 1996 & & & & & & 1947 & 6.0 & 1962 & 5.4 & 1947 & 7.1 & 1962 & 5.9 \\
\hline AFRICA & Côte d'Ivoire & $\mathrm{Cl}$ & 10.0 & 43.5 & 2 & 1980 & 1994 & & & & & 1936 & 6.5 & 1960 & 4.2 & 1931 & 7.0 & 1960 & 5.7 \\
\hline AFRICA & Egypt & EG & 31.9 & 42.8 & 6 & 1980 & 1988 & 1992 & 1995 & 2000 & 2003 & 1931 & 6.6 & 1969 & 3.1 & 1931 & 7.2 & 1969 & 3.9 \\
\hline AFRICA & Ethiopia & ET & 4.6 & 14.7 & 1 & 1992 & & & & & & 1943 & 6.1 & 1958 & 3.4 & 1943 & 7.5 & 1958 & 6.0 \\
\hline AFRICA & Gabon & GA & 11.4 & 80.1 & 1 & 2000 & & & & & & 1951 & 6.4 & 1966 & 3.6 & 1951 & 6.2 & 1966 & 5.2 \\
\hline AFRICA & Ghana & $\mathrm{GH}$ & 15.4 & 43.9 & 5 & 1979 & 1988 & 1993 & 1998 & 2003 & & 1930 & 6.2 & 1969 & 3.1 & 1930 & 6.7 & 1969 & 5.3 \\
\hline AFRICA & Guinea & GN & 6.7 & 31.0 & 1 & 2005 & & & & & & 1956 & 6.1 & 1971 & 4.0 & 1956 & 6.7 & 1971 & 5.3 \\
\hline AFRICA & Kenya & KE & 5.6 & 19.9 & 6 & 1977 & 1988 & 1993 & 1998 & 2003 & 2008 & 1933 & 8.2 & 1974 & 2.8 & 1928 & 7.9 & 1974 & 4.9 \\
\hline AFRICA & Lesotho & LS & 1.8 & 19.5 & 2 & 1977 & 2004 & & & & & 1933 & 4.8 & 1965 & 2.4 & 1955 & 5.4 & 1970 & 3.8 \\
\hline AFRICA & Liberia & LB & 13.0 & 44.3 & 1 & 1986 & & & & & & 1937 & 6.8 & 1952 & 4.9 & 1942 & 6.5 & 1952 & 4.5 \\
\hline AFRICA & Madagascar & MD & 7.8 & 27.1 & 3 & 1992 & 1997 & 2003 & & & & 1943 & 5.7 & 1969 & 3.3 & 1943 & 7.8 & 1969 & 4.6 \\
\hline AFRICA & Malawi & MW & 3.5 & 14.6 & 3 & 1992 & 2000 & 2004 & & & & 1948 & 7.7 & 1970 & 3.5 & 1943 & 7.3 & 1970 & 5.4 \\
\hline AFRICA & Mali & $M L$ & 8.5 & 28.4 & 4 & 1987 & 1995 & 2001 & 2006 & & & 1943 & 7.1 & 1972 & 4.4 & 1938 & 0.0 & 1972 & 6.1 \\
\hline AFRICA & Morocco & MA & 26.2 & 53.3 & 4 & 1980 & 1987 & 1992 & 2003 & & & 1931 & 6.5 & 1969 & 1.8 & 1931 & 7.6 & 1969 & 3.2 \\
\hline AFRICA & Mozambique & MZ & 3.5 & 29.1 & 2 & 1997 & 2003 & & & & & 1948 & 5.0 & 1969 & 4.0 & 1948 & 5.7 & 1969 & 5.3 \\
\hline AFRICA & Namibia & NM & 13.4 & 32.4 & 2 & 1992 & 2000 & & & & & 1948 & 3.9 & 1966 & 2.7 & 1943 & 6.4 & 1966 & 4.3 \\
\hline AFRICA & Niger & $\mathrm{NI}$ & 4.9 & 16.2 & 3 & 1992 & 1998 & 2006 & & & & 1943 & 7.8 & 1972 & 5.0 & 1943 & 8.0 & 1972 & 6.3 \\
\hline AFRICA & Rwanda & RW & 2.1 & 14.9 & 3 & 1992 & 2000 & 2005 & & & & 1948 & 5.5 & 1971 & 3.9 & 1943 & 8.2 & 1971 & 5.0 \\
\hline AFRICA & Senegal & SN & 17.2 & 40.3 & 5 & 1978 & 1986 & 1992 & 1997 & 2005 & & 1934 & 6.4 & 1971 & 3.1 & 1929 & 7.3 & 1971 & 4.6 \\
\hline AFRICA & South Africa & ZA & 42.2 & 56.9 & 1 & 1998 & & & & & & 1949 & 3.1 & 1964 & 2.4 & 1949 & 5.2 & 1964 & 3.9 \\
\hline AFRICA & Sudan & SD & 6.8 & 32.5 & 2 & 1978 & 1989 & & & & & 1929 & 6.2 & 1955 & 4.9 & 1929 & 6.0 & 1955 & 5.6 \\
\hline AFRICA & Togo & TG & 4.4 & 32.9 & 2 & 1988 & 1998 & & & & & 1944 & 6.0 & 1964 & 3.4 & 1939 & 7.6 & 1964 & 5.5 \\
\hline AFRICA & Tunisia & TN & 32.3 & 63.4 & 2 & 1978 & 1988 & & & & & 1929 & 6.9 & 1954 & 3.7 & 1929 & 7.2 & 1954 & 5.6 \\
\hline
\end{tabular}




\begin{tabular}{|c|c|c|c|c|c|c|c|c|c|c|c|c|c|c|c|c|c|c|c|}
\hline AFRICA & Uganda & UG & 2.8 & 12.1 & 3 & 1988 & 1995 & 2000 & & & & 1944 & 7.5 & 1966 & 4.0 & 1939 & 7.8 & 1966 & 6.1 \\
\hline AFRICA & United Rep. Of Tanzania & TZ & 3.5 & 22.3 & 3 & 1991 & 1996 & 1999 & & & & 1947 & 5.5 & 1965 & 3.1 & 1942 & 7.1 & 1965 & 5.4 \\
\hline AFRICA & Zambia & ZM & 11.5 & 34.8 & 2 & 1992 & 1996 & & & & & 1948 & 6.3 & 1962 & 4.5 & 1943 & 8.0 & 1962 & 5.7 \\
\hline AFRICA & Zimbabwe & $\mathrm{ZW}$ & 10.6 & 33.8 & 1 & 1999 & & & & & & 1955 & 3.9 & 1965 & 2.8 & 1950 & 7.0 & 1965 & 4.0 \\
\hline ASIA & Bangladesh & $\mathrm{BD}$ & 4.3 & 23.6 & 3 & 1975 & 2000 & 2004 & & & & 1931 & 6.5 & 1970 & 3.2 & 1926 & 6.9 & 1970 & 3.9 \\
\hline ASIA & Cambodia & $\mathrm{KH}$ & 10.2 & 18.6 & 1 & 2000 & & & & & & 1951 & 4.4 & 1966 & 2.9 & 1951 & 5.8 & 1966 & 3.9 \\
\hline ASIA & India & IA & 17.0 & 27.7 & 2 & 1992 & 2000 & & & & & 1943 & 4.2 & 1966 & 2.8 & 1943 & 5.4 & 1966 & 3.9 \\
\hline ASIA & Indonesia & ID & 12.4 & 42.0 & 3 & 1976 & 1987 & 1991 & & & & 1927 & 5.8 & 1957 & 3.3 & 1927 & 5.2 & 1957 & 3.7 \\
\hline ASIA & Jordan & JO & 37.0 & 79.8 & 1 & 1997 & & & & & & 1948 & 7.2 & 1963 & 5.1 & 1948 & 8.9 & 1963 & 5.7 \\
\hline ASIA & Nepal & NP & 2.7 & 13.4 & 3 & 1976 & 1996 & 2001 & & & & 1932 & 5.9 & 1967 & 3.0 & 1927 & 5.8 & 1967 & 4.4 \\
\hline ASIA & Pakistan & PK & 17.5 & 33.2 & 2 & 1975 & 1990 & & & & & 1926 & 7.0 & 1956 & 4.9 & 1926 & 6.9 & 1956 & 5.4 \\
\hline ASIA & Philippines & $\mathrm{PH}$ & 27.1 & 48.0 & 3 & 1978 & 2003 & 2008 & & & & 1929 & 6.2 & 1974 & 2.7 & 1929 & 7.4 & 1974 & 3.6 \\
\hline ASIA & Sri Lanka & LK & 15.3 & 18.4 & 2 & 1975 & 1987 & & & & & 1926 & 5.7 & 1953 & 2.9 & 1926 & 6.1 & 1953 & 3.4 \\
\hline ASIA & Thailand & $\mathrm{TH}$ & 16.5 & 31.4 & 1 & 1987 & & & & & & 1938 & 4.1 & 1953 & 2.5 & 1938 & 5.4 & 1953 & 2.9 \\
\hline ASIA & Viet Nam & VN & 11.6 & 24.4 & 2 & 1997 & 2002 & & & & & 1948 & 3.6 & 1963 & 2.1 & 1948 & 4.8 & 1968 & 2.6 \\
\hline ASIA & Yemen & YE & 5.8 & 26.3 & 1 & 1991 & & & & & & 1942 & 7.9 & 1957 & 6.4 & 1942 & 8.0 & 1957 & 6.7 \\
\hline LACarr & Bolivia & BO & 33.8 & 61.8 & 5 & 1989 & 1993 & 1998 & 2003 & 2008 & & 1940 & 4.9 & 1974 & 2.8 & 1940 & 7.1 & 1974 & 4.9 \\
\hline LACarr & Brazil & BR & 36.2 & 81.2 & 2 & 1986 & 1996 & & & & & 1942 & 3.7 & 1962 & 2.3 & 1942 & 6.6 & 1962 & 3.5 \\
\hline LACarr & Colombia & $\mathrm{CO}$ & 32.7 & 72.1 & 5 & 1976 & 1986 & 1990 & 1995 & 2004 & & 1927 & 6.4 & 1970 & 2.2 & 1927 & 7.4 & 1961 & 3.9 \\
\hline LACarr & Dominican Rep. & DR & 23.7 & 61.7 & 6 & 1975 & 1986 & 1991 & 1996 & 1999 & 2002 & 1931 & 5.2 & 1968 & 2.8 & 1926 & 7.7 & 1968 & 3.5 \\
\hline LACarr & Ecuador & EC & 28.3 & 60.3 & 1 & 1979 & & & & & & 1930 & 5.7 & 1945 & 3.7 & 1930 & 7.6 & 1945 & 6.3 \\
\hline LACarr & Guatemala & GU & 25.1 & 45.1 & 3 & 1987 & 1995 & 1998 & & & & 1943 & 4.4 & 1964 & 3.5 & 1943 & 6.6 & 1964 & 5.3 \\
\hline LACarr & Haiti & HT & 12.2 & 35.6 & 3 & 1977 & 1994 & 2000 & & & & 1933 & 4.3 & 1966 & 2.8 & 1928 & 6.3 & 1966 & 5.4 \\
\hline LACarr & M exico & $M X$ & 42.7 & 74.7 & 2 & 1976 & 1987 & & & & & 1927 & 6.4 & 1953 & 3.4 & 1932 & 6.1 & 1953 & 5.7 \\
\hline LACarr & Nicaragua & NC & 35.2 & 54.7 & 2 & 1997 & 2001 & & & & & 1948 & 4.8 & 1967 & 3.0 & 1948 & 7.6 & 1967 & 4.7 \\
\hline LACarr & Panama & PA & 35.8 & 62.2 & 1 & 1975 & & & & & & 1926 & 4.9 & 1941 & 3.1 & 1926 & 6.9 & 1941 & 5.4 \\
\hline $\begin{array}{l}\text { LACarr } \\
\text { LACarr }\end{array}$ & $\begin{array}{l}\text { Paraguay } \\
\text { Peru }\end{array}$ & $\begin{array}{l}\text { PY } \\
\text { PE }\end{array}$ & $\begin{array}{l}34.6 \\
41.0\end{array}$ & $\begin{array}{l}55.3 \\
73.0\end{array}$ & $\begin{array}{l}2 \\
10\end{array}$ & $\begin{array}{l}1979 \\
1977\end{array}$ & $\begin{array}{l}1990 \\
1986\end{array}$ & 1996 & 2000 & 2004 & $\begin{array}{l}2007- \\
2012\end{array}$ & $\begin{array}{l}1930 \\
1928\end{array}$ & $\begin{array}{l}4.7 \\
6.3\end{array}$ & $\begin{array}{l}1956 \\
1978\end{array}$ & $\begin{array}{l}3.3 \\
2.2\end{array}$ & $\begin{array}{l}1930 \\
1928\end{array}$ & $\begin{array}{l}7.5 \\
7.8\end{array}$ & $\begin{array}{l}1956 \\
1978\end{array}$ & $\begin{array}{l}5.6 \\
3.5\end{array}$ \\
\hline
\end{tabular}

Sources: WHS \& DHS, United Nations' World Population and Urbanization Prospects and historical estimates. 
Figure 5: Three estimates of the national-level total cohort fertility as implied by the chaining of cohort PPRs, by cohort age-specific fertility rates, and by back-translation of period TFRs (by 30 years), cohorts 1900-1980 in Asian, Latin American and African countries

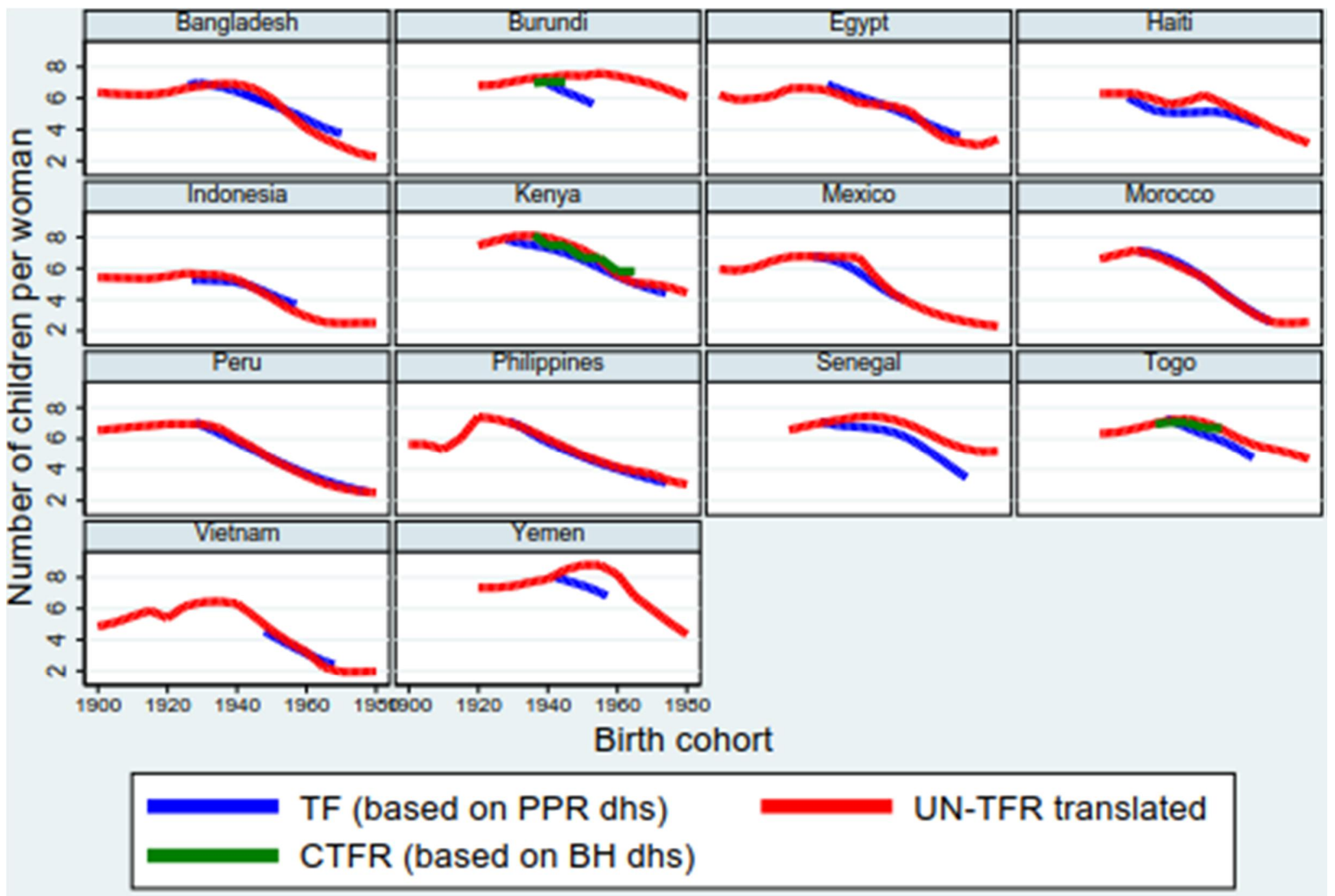

Sources: WFS \& DHS, UN World Population Prospects 2015, Sneeringer (2009) 
Rural cohort fertility trends over the course of the national fertility transitions are given in Fig. 6 for comparison purposes with Fig. 1 in the main body of this manuscript.

Figure 6: Average and country-specific trends in rural cohort fertility over the course of the national fertility transitions (onset =year 0), cohorts 1925-1978 in African, Asian and Latin American countries.

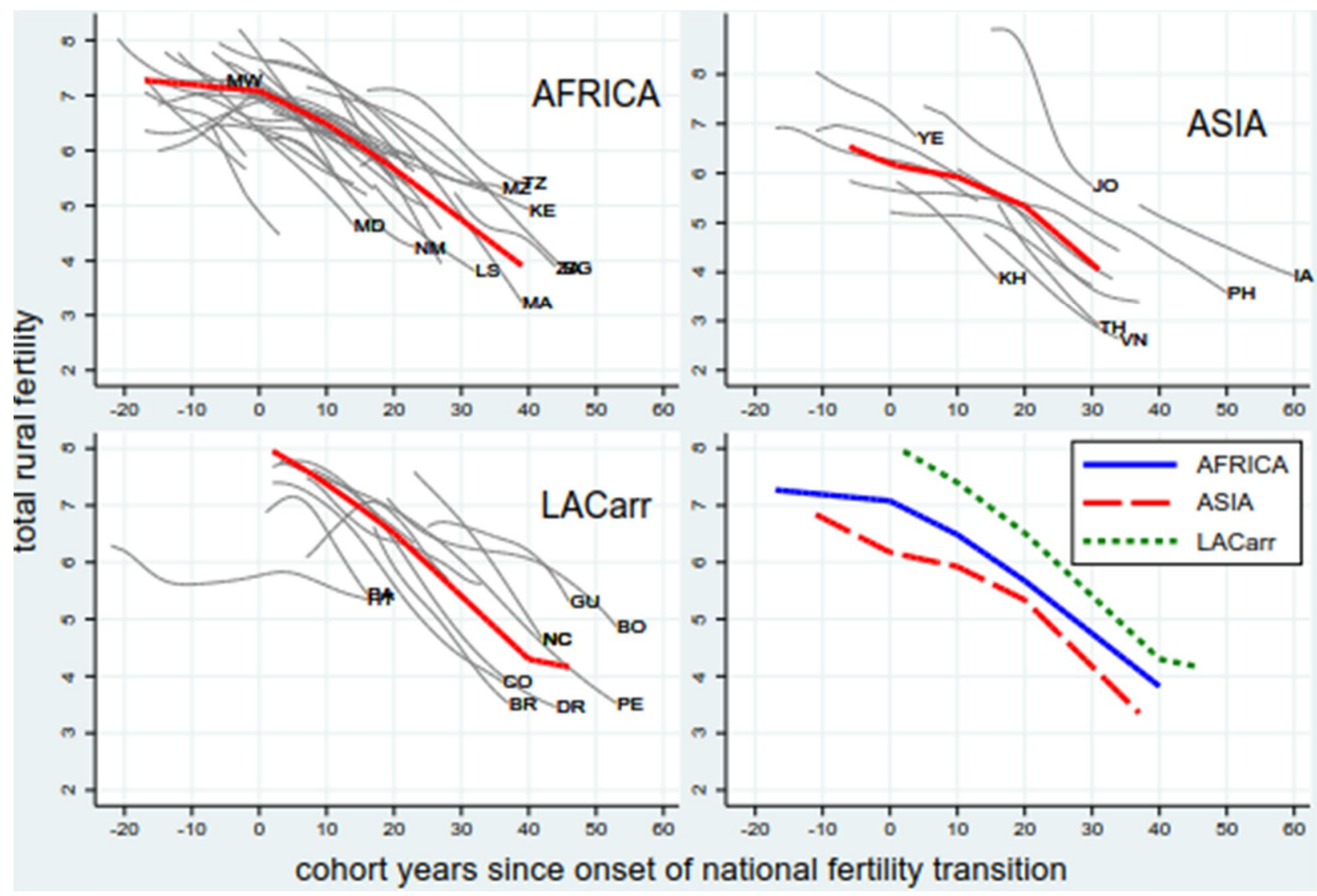

Sources: WFS \& DHS

Excluding the migrants who moved across urban-rural borders after childhood from our study population evidently leads to a lower estimate of cohort fertility in urban areas. This concerns mainly the early transition stages in less urbanized countries because in-migrants represent a larger share of the urban populations. In Africa, the difference between our TF estimates for non-migrants and the comparative estimate including all urban residents at the survey date is typically around 0.5 children (but can reach more than 1 child in Western and Central Africa; Fig. 7). These differences underline the importance of excluding migrants in order to better reveal long-term fertility trends and gradients as driven by place-specific socialization and structural changes. The impact of in-migrants on urban fertility levels is more limited in Latin America and Asia, which is probably due, respectively, to the higher level of urbanization and a greater selection of migrants among less fertile women in rural areas. 
Figure 7: Average and country-specific differences in the estimates of cohort fertility of all urban residents (at the time of the surveys) and among non-migrant women socialized in urban areas, over the course of the national fertility transitions (onset =year 0), cohorts 1925-1978 in African, Asian and Latin American countries

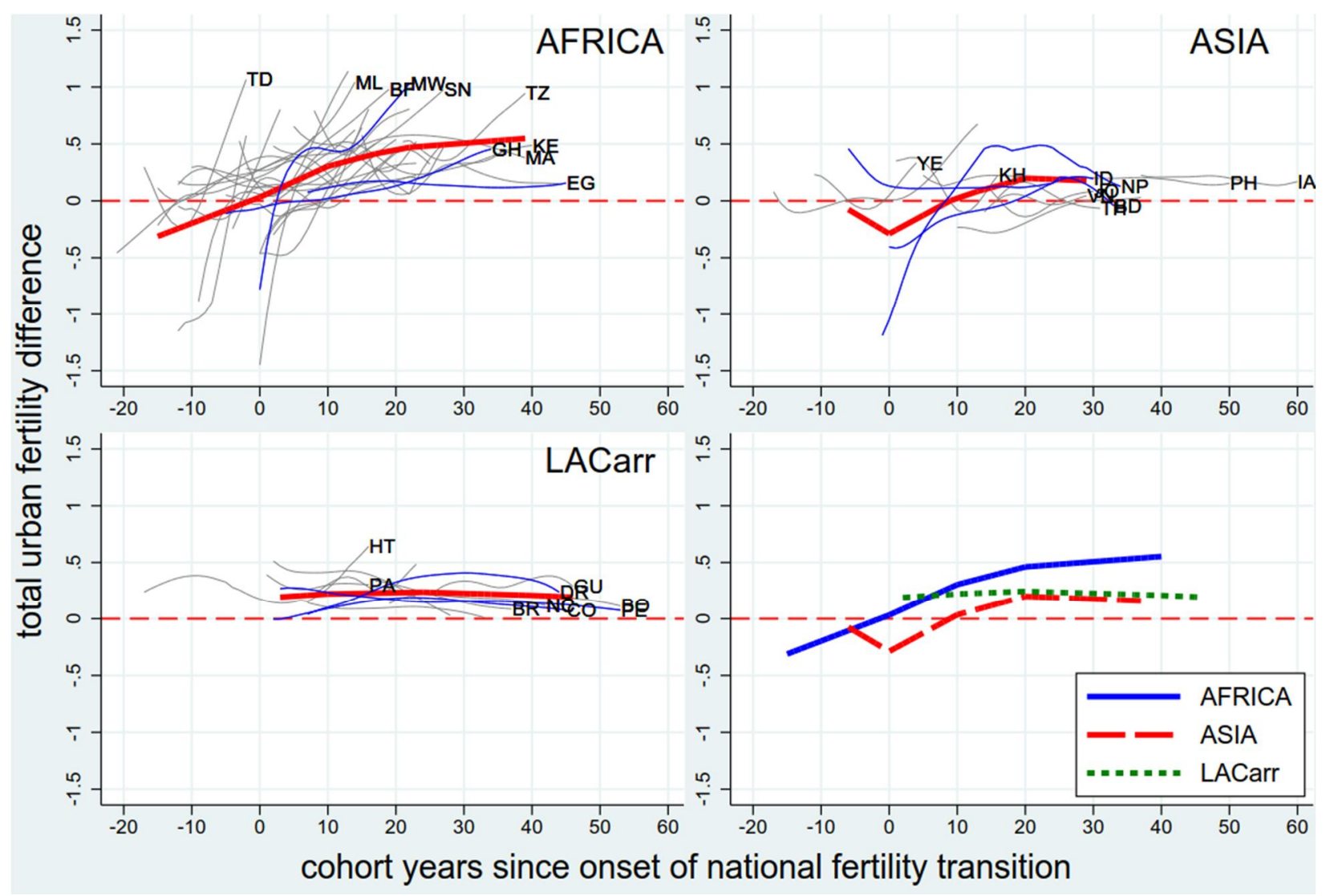

Source: WHS \& DHS. 


\section{References}

Bocquier, P. 2005. World Urbanization Prospects: an alternative to the UN model of projection compatible with the mobility transition theory. Demographic Research 12(9):197-236.

Bongaarts, J., \& S.C. Watkins. 1996. Social Interactions and Contemporary Fertility Transitions. Population and Development Review 22(4):639-682.

Brass, W., \& F. Juarez. 1983. Censored Cohort Parity Progression Ratios from Birth Histories. Asian and Pacific Census Forum 10(1):5-13.

Brockerhoff, M. 1998. Migration and the Fertility Transition in African Cities. in R.E. Bilsborrow Migration, urbanization, and development: new directions and issues (pp. 357-390). Norwell, M assachusetts: Kluwer Academic Publishers.

Bryant, J. 2007. Theories of Fertility Decline and the Evidence from Development Indicators. Population and Development Review 33(1):101-127.

Caldwell, J.C. 2001. The Globalization of Fertility Behavior. Population and Development Review 27(Supplement: Global Fertility Transition):93-115.

Caldwell, J.C., I.O. Orubuloye, \& P. Caldwell. 1992. Fertility Decline in Africa: A New Type of Transition? Population and Development Review 18(2):211-242.

Casterline, J.B. 2001. The Pace of Fertility Transition: National Patterns in the Second Half of the Twentieth Century. Population and Development Review 27(Supplement: Global Fertility Transition):1752.

Casterline, J.B., \& C. Odden. 2016. Trends in Inter-Birth Intervals in Developing Countrie 1865-2014. Population and Development Review 42(2):173-184.

Chen, N., P. Valente, \& H. Zontnik. 1998. What Do We Know about Recent Trends in Urbanization? in R.E. Bilsborrow Migration, urbanization, and development: new directions and issues (pp. 59-88). Norwell: Kluwer Academic Publishers.

Christiaensen, L., M. Gindelsky, \& R. Jedwab. 2013. Rural Push, Urban Pull or... Urban Push? New Historical Evidence from 40 Developing Countries. World Bank - Africa Region - Working Paper Series.

Cleland, J., \& C. Wilson. 1987. Demand Theories of the Fertility Transition: an Iconoclastic View. Population Studies 41(1):5-30.

Coale, A.J. 1973. The Demographic Transition. in International Union for the Scientific Study of Population (IUSSP) Internatonal Population Conference 1973. Liège: IUSSP.

Corker, J. 2016. Fertility and Child M ortality in Urban West Africa: Leveraging Geo-Referenced Data to M ove Beyond the Urban/Rural Dichotomy. Population, Space and Place:n/a-n/a.

Dyson, T., \& M. Murphy. 1985. The Onset of Fertility Transition. Population and Development Review 11(3):399-440.

Fargues, P. 1988. Urbanisation et transition démographique : Quelles interrelations en Afrique ? Espace, populations, sociétés 1988-2:183-198.

Findlay, S.E. 1980. A Suggested Framework for Analysis of Urban-Rural Fertility Differentials with an Illustration of the Tanzanian Case. Population and Evironment 3(3/4):237-261.

Findley, S. 1978. Patterns of Urban-Rural Fertility Differentials in Developing Countries: A Suggested Framework. Washington, D.C.: U.S. Agency for International Development. 
Galloway, P.R., R.D. Lee, \& E.A. Hammel. 1998. Urban versus Rural: Fertility Decline in the Cities and Rural Districts of Prussia, 1875 to 1910. European Journal of Population 14(3):209-264.

Garenne, M., \& V. Joseph. 2002. The Timing of the Fertility Transition in Sub-Saharan Africa. World Development 30(10):1835-1843.

Goldstein, S., \& A. Goldstein. 1981. The Impact of Migration on Fertility: an 'Own Children' Analysis for Thailand. Population Studies 35(2):265-284.

Hägerstrand, T. 1952. The Propagation of Innovation Waves. Lund Studies in Geography - Serie B Human Geography 4:23.

Johnson-Hanks, J. 2007. Natural Intentions: Fertility Decline in the Africa Demographic and Health Surveys. American Journal of Sociology 112(4):1008-1043.

Kirk, D., \& B. Pillet. 1998. Fertility Levels, Trends, and Differentials in Sub-Saharan Africa in the 1980s and 1990s. Studies in Family Planning 29(1):1-22.

Klüsener, S., F. Scalone, \& M. Dribe. 2017. Exploring the Role of Communication in Shaping Fertility Transition Pattern in Space and Time. in A. Grow, \& J. Van Bavel Agent-Based Modelling in Popluation Studies (pp. 369-403): Springer International Publishing Switzerland.

Lesthaeghe, R. 1980. On the Social Control of Human Reproduction. Population and Development Review 6(4):527-548.

M artine, G., J.E. Alves, \& S. Cavenaghi. 2013. Urbanization and fertility decline: Cashing in on structural change. Pp. 44 in IIED Working Paper. London: International Institute for Environment and Development.

M ichel M. Garenne. 2008. Fertility Changes in Sub-Saharan Africa. DHS Comparative Reports 18:111.

M ontgomery, M.R., R. Stren, B. Cohen, \& H.E. Reed. 2003. Cities Transformed: Demographic Change and Its Implications in the Developing World. Washington D.C.: The National Academies Press.

Moultrie, T.A., R. Dorrington, A. Hill, K. Hill, I. Timaeus, \& B. Zaba. 2013. Tools for Demographic Estimation. Paris: International Union for the Scientific Study of Population (IUSSP).

Moultrie, T.A., T.S. Sayi, \& I.M. Timaeus. 2012. Birth intervals, postponement, and fertility decline in Africa: A new type of transition. Population Studies 66(3):241-258.

Notestein, F.W. 1953. Economic problems of population change. Presented at Proceedings of the Eighth International Conference of Agricultural Economists, London.

Preston, S.H. 1979. Urban Growth in Developing Countries: A Demographic Reappraisal. Population and Development Review 5(2):195-215.

Rodriguez, G. 1996. The Spacing and Liming Components of the Fertility Transition in Latin America. in J.M. Gnuzman, S. Sigh, G. Rodriguez, \& E.A. Pantelids The Fertiltiy Transition in Latin America (pp. 27-47). Oxford: Oxford University Press.

Schoumaker, B. 2014. Quality and Consistency of DHS Fertility Estimates, 1990 to 2012. DHS M ethodological Reports 12:122.

Shapiro, D., \& B.O. Tambashe. 2000. Fertility Transition in Urban and Rural Areas of Sub-Saharan Africa.

Sharlin, A. 1986. Urban-Rural Differences in Fertility in Europe during the Demographic Transition. in Ansley J. Coale, \& S.C. Watkins The Decline of Fertility in Europe (pp. 234-260). Princeton, New Jersey: Princeton University Press.

Sneeringer, S.E. 2009. Fertility Transition in Sub-Saharan Africa: A Comparative Analysis of Cohort Trends in 30 Countries. Pp. 23 in DHS Comparative Reports. Calverton, Maryland, USA: ICF M acro. 
Tabutin, D. 2000. La ville et l'urbanisation dans les théories du changement démographique. in Document de travail. Louvain-la-Neuve: Département des Sciences de la Population et du Développement, Université catholique de Louvain.

Toulemon, L. 2004. La fécondité des immigrées: nouvelles données, nouvelle approche. Population \& Sociétés 400(Avril).

United Nations. 1983. Manual X: Indirect Techniques for Demographic Estimation. New York: United Nations.

—. 1987. Fertility Behaviour in the Context of Development - Evidence from the World Fertility Survey. New York: United Nations Publications.

White, M.J., E. Tagoe, C. Stiff, K. Adazu, \& D. Jordan Smith. 2005. Urbanization and the fertility transition in Ghana. Population Research and Policy Review 24:59-83. 